\section{Motion in Limine}

Robert L. Heilbronner

Chicago Neuropsychology Group, 333

N. Michigan Avenue, \#1801, Chicago, IL, USA

\section{Definition}

Motion in limine, meaning "on the threshold" in Latin, is a request submitted to the court before trial in an attempt to exclude evidence from the proceedings. It is usually made by a party when simply the mention of the evidence would prejudice the jury against that party, even if the judge later instructed the jury to disregard the evidence. For example, the defendant may ask the court to rule that evidence of a prior conviction that occurred a long time ago should not be allowed into evidence at the trial because it would be more prejudicial than probative. If the motion is granted, then evidence regarding the conviction could not be mentioned in front of the jury, without first approaching the judge outside the hearing of the jury and obtaining permission. The violation of a motion in limine can result in the court declaring a mistrial.

There are three types of motions in limine: (1) inclusionary, a motion asking the court to have something included in the trial; (2) exclusionary, a motion asking the court to have something excluded in the trial; and (3) preclusionary, a motion asking the court to have something precluded in the trial. In most courts, lawyers must file any motions in limine fifteen (15) days before trial. Many judges view motions in limine as a form of preliminary injunction. In other words, the moving party in a personal injury accident case would be irreparably harmed by waiting for an in-trial objection. Consequently, the standard in many states for granting of a motion in limine in an accident case is whether any reference to the evidence the moving party seeks to exclude is so prejudicial that the nonmoving party may not make reference to it. This is particularly important to the personal injury attorney who does not want the defense attorney referencing the evidence at issue in defendant's opening statement (where objection is more difficult). Judges are typically reticent to exclude broad categories of evidence but may be receptive to a narrower request.

\section{Cross-References}

Motion for Summary Judgment

\section{References and Readings}

Celotex Corp. v. Catrett 477 U.S. 317, 324 (1986).

Federal Rules of Civil Procedure, No. 56. 